\title{
Preparation, Photocatalytic Activity, and Recovery of Magnetic Photocatalyst for Decomposition of Benzoic Acid
}

\author{
Te-Li Su, ${ }^{1}$ Chyow-San Chiou, ${ }^{2}$ and Hua-Wei Chen ${ }^{1}$ \\ ${ }^{1}$ Department of Cosmetic Application and Management, St. Mary's Medicine, Nursing and Management College, Yilan 266, Taiwan \\ ${ }^{2}$ Department of Environmental Engineering, National I-Lan University, I-lan 26047, Taiwan
}

Correspondence should be addressed to Hua-Wei Chen, superlemi@smc.edu.tw

Received 15 May 2011; Revised 2 August 2011; Accepted 17 August 2011

Academic Editor: Jiaguo Yu

Copyright (C) $2012 \mathrm{Te}-\mathrm{Li}$ Su et al. This is an open access article distributed under the Creative Commons Attribution License, which permits unrestricted use, distribution, and reproduction in any medium, provided the original work is properly cited.

\begin{abstract}
The purpose of this paper is to determine the experimental parameters of $\mathrm{TiO}_{2}$ preparation for optimizing the removal rate of benzoic acid by magnetic photocatalytic oxidation process. Therefore, this paper intended to prepare a magnetic photocatalyst $\left(\mathrm{TiO}_{2} / \mathrm{SiO}_{2} / \mathrm{Fe}_{3} \mathrm{O}_{4}\right)$ that can be recycled using an external magnetic field. Magnetic photocatalysts are characterized by X-ray diffraction (XRD), vibrating sample magnetometry (VSM), and Fourier transform infrared (FTIR) spectroscopy. The optimal the experimental parameters of $\mathrm{TiO}_{2}$ preparation for the removal rate of photocatalysts were concluded as $\mathrm{pH}$ is 3 , weight ratio of $\mathrm{TiO}_{2} / \mathrm{SiO}_{2}\left(\mathrm{Fe}_{3} \mathrm{O}_{4}\right)$ is 1 , and calcined temperature of $\mathrm{TiO}_{2} / \mathrm{SiO}_{2} / \mathrm{Fe}_{3} \mathrm{O}_{4}$ is $350^{\circ} \mathrm{C}$. Furthermore, the paramagnetic behaviors of the prepared $\mathrm{TiO}_{2} / \mathrm{SiO}_{2} / \mathrm{Fe}_{3} \mathrm{O}_{4}$ gave rise to the magnetic photocatalyst, which could be separated more easily through the application of a magnetic field for reuse.
\end{abstract}

\section{Introduction}

Benzoic acid is one of the oldest chemical preservatives used in food, cosmetics, and drugs. Benzoic acid can also be detected in car exhaust gases, cigarettes, phytochemically degraded benzoic acid esters in fragrance ingredients, wastewater from wood production industries, foundry waste leachates, and ashes from municipal incinerators [1]. A common objective of AOPs [2-5] is to produce a large amount of radicals (especially $\mathrm{OH}$ ), in order to oxidize organic matter. Semiconductor photocatalysis has become an increasingly promising technology in environmental remediation [6-8]. Various types of photocatalysts, titanium dioxide is now under intensive investigation for practical application in antimicrobial, deodorization, air and water purifications, and wastewater treatment due to its favorable physical/chemical properties, low cost, ease of availability, and high stability [9]. Typically, catalytic ozonation and photocatalytic oxidation are conducted in a suspension of submicrometer-sized particles $[3,4,10]$ and, therefore, requires an additional separation step to remove the catalyst from treated water, which presents a major drawback in the application of $\mathrm{UV} / \mathrm{TiO}_{2}$ processing for treating wastewater.
One approach in overcoming this drawback has been the development of a magnetic photocatalyst that allows for easy catalyst removal by using an external magnet, simplifying the downstream recovery stage $[11,12] . \mathrm{Fe}_{3} \mathrm{O}_{4}$ has been generally used as a very important ferromagnetic material for wide application (pigment, recording materials, catalysis, magnetocaloric refrigeration, and drug-delivery carrier) due to its low cost, good hydrophilic and biocompatible properties. [4, 12-14]. However, a direct contact between magnetic iron oxide and $\mathrm{TiO}_{2}$ photocatalyst usually gives rise to an unfavorable heterojunction, leading to an increase in electron-hole recombination and photodissolution [15]. Therefore, it is necessary to shield the magnetic iron oxide from direct contacts with titania by introducing a barrier layer. Silica is one of most commonly used support material in catalysis due to the stability, protection of core (iron oxide) and surface modification $[15,16]$. Thus, this study investigates the reaction behavior of photocatalytic processes with magnetic photocatalyst $\left(\mathrm{Fe}_{3} \mathrm{O}_{4}\right.$ core and $\mathrm{TiO}_{2} / \mathrm{SiO}_{2}$ shell) in treating wastewater to enhance the activity of the prepared magnetic photocatalyst and recover the photocatalyst.

There have been many parameters, such as $\mathrm{pH}$, weight ratio, and calcined temperature, related to the Taguchi 
method $[17,18]$ to removal rates. Efficiently determining the critical factors can improve the efficiency of the photocatalysts. The traditional trial-and-error method lacks proper overall planning of experimental parameters, thus, while it could acquire the most comprehensive experimental data, discussion and analysis of the correlation between experimental parameters was lacking. An experiment that tests all parameters takes an excessive amount of time and the photocatalysts conditions are difficult to control. This research has, therefore, applied the Taguchi method [1922 ] to the removal rate of benzoic acid by a UV/magnetic photocatalyst process and the design of a series of experimental principles. The most influential parameters for removal rate of benzoic acid by UV/magnetic photocatalyst process were selected and matched with a customized experimental plan, in order that the experimental parameters of the photocatalysts could be analyzed, which was used to optimize the experimental parameters and improve the removal rate.

Therefore, in this paper, the Taguchi method was applied to determine the parameters for the optimal removal rate of benzoic acid by the UV/magnetic photocatalyst process. However, there are many experimental parameters and the process is complicated, the selection relies completely on experienced researchers, or by the trial and error method, in order to change the experimental parameters of the photocatalyst/UV process through multiple error attempts. This method is not only time consuming, increasing the trial time, but also simultaneously results in greater cost and difficulty in accumulating and passing on such experience.

\section{Material and Methods}

2.1. Experimental Apparatus. All experimental solutions were prepared with deionized water and reagent-grade chemicals. The photocatalytic activates under UV light illumination were evaluated by measuring the decomposition rate of benzoic acid. The batch cylindrical photoreactor was made of Pyrex glass with an effective volume of 1.5 liter and was water-jacketed to maintain the solution temperature, as illustrated in Figure 1. The UV light illumination was conducted using two black lamps (Sparkie BLB-S8W) of $8 \mathrm{~W}$ power with the maximum intensity at $365 \mathrm{~nm}$. Photocatalytic decomposition of benzoic acid was assumed to be started when the prewarmed light source within the reactor was turned on. The aqueous solution containing benzoic acid was initially transferred to the column reactor, and the $\mathrm{pH}$ value of the solution was controlled by adding sodium hydroxide and/or perchlorates during the entire reaction time. Perchlorates and nitrates had very little effect of photocatalytic reaction, and sulfates or phosphates, even at millimolar concentrations, were found to be rapidly adsorbed by the catalyst and to reduce the rate of photocatalytic reaction by $20-70 \%$ [23]. Aliquots of the reaction solution were sampled at intermittent periods of reaction time. The samples were analyzed for concentrations of benzoic acid with a liquid chromatography equipped with a KANUER Smartline UV detector 2500, Alpha 10 Isocratic Pump, and SUPELCO 516 C-18 column.

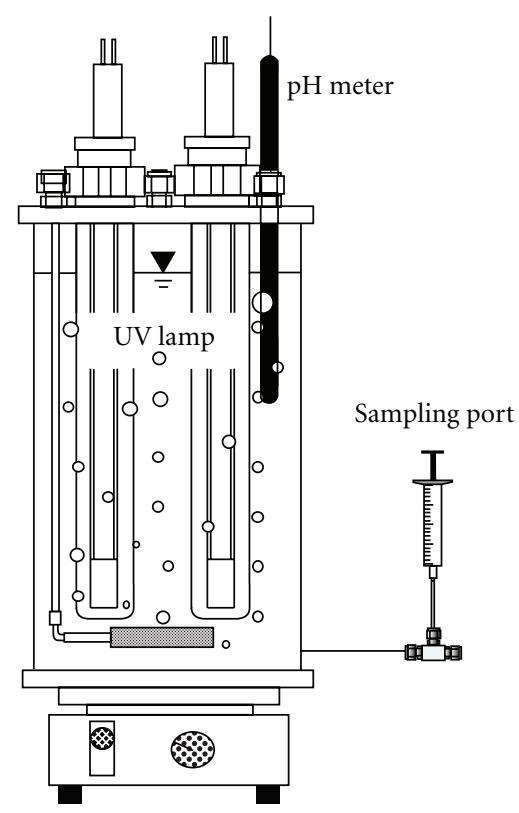

Figure 1: Experimental sketch of $\mathrm{UV} / \mathrm{TiO}_{2} / \mathrm{SiO}_{2} / \mathrm{Fe}_{3} \mathrm{O}_{4}$ system.

2.2. Catalyst Preparation. Magnetite $\left(\mathrm{Fe}_{3} \mathrm{O}_{4}\right)$ was purchased from Sigma-Aldrich (St. Louis, Mo, USA) and used without any further purification. A total of $1.08 \mathrm{~L}$ of aqueous solution containing $20 \mathrm{~g}$ of $\mathrm{Fe}_{3} \mathrm{O}_{4}$ particles was contained in a 2 - $\mathrm{L}$ beaker at $90^{\circ} \mathrm{C}$; the $\mathrm{pH}$ was maintained at 9.5 with $0.1 \mathrm{~N} \mathrm{NaOH}$, while being stirred by a mechanical stirrer. The appropriate amount of Degussa P-25 $\mathrm{TiO}_{2}$ particles and $\mathrm{Na}_{2} \mathrm{O} \cdot \mathrm{nSiO}_{2}$ was dispersed and dissolved, respectively, in $100 \mathrm{~mL}$ of deionized water; the aqueous solution was then mixed with the aqueous solution containing magnetite $\left(\mathrm{Fe}_{3} \mathrm{O}_{4}\right)$ with a mechanical stirrer for $10 \mathrm{~min}$ The magnetic photocatalysts (i.e., $\mathrm{TiO}_{2} / \mathrm{SiO}_{2} / \mathrm{Fe}_{3} \mathrm{O}_{4}$ ) were dried at $105^{\circ} \mathrm{C}$ after the $\mathrm{pH}$ value of the slurry solution was maintained at 8 with $5 \mathrm{~N} \mathrm{H}_{2} \mathrm{SO}_{4}$ Finally, the $\mathrm{TiO}_{2} / \mathrm{SiO}_{2} / \mathrm{Fe}_{3} \mathrm{O}_{4}$ was placed in an oven isothermally at $350^{\circ} \mathrm{C}, 550^{\circ} \mathrm{C}$, and $750^{\circ} \mathrm{C}$ for 2 hours with nitrogen-pass, respectively.

2.3. Instrumental Analysis. The morphology and specific BET surface area of the $\mathrm{TiO}_{2}$ were determined by a Rigaku RTP 300 X-ray diffractometer (XRD) and a Micromeritics ASAP 2000 analyzer, respectively. The functional groups of the synthesized magnetic photocatalysts $\left(\mathrm{TiO}_{2} / \mathrm{SiO}_{2} / \mathrm{Fe}_{3} \mathrm{O}_{4}\right)$ were confirmed using an FTIR spectrometer (Spectrum 100, Perkin Elmer, USA). The magnetic behavior was analyzed using a vibrating sample magnetometer (VSM, Lake Shore 7407, Lake Shore, USA). The magnetic properties and functional groups of the photocatalysts were determined by a vibrating sample magnetometer (Lake Shore, 7407) and a Fourier Transform Infrared Spectrophotometer (Perkin Elmer, 1600), respectively. For experiments related to the photodecomposition of benzoic acid, the degradation of benzoic acid present in the reaction solution was analyzed by Spectra-Physics P1000 HPLC equipped with an UV detector. 
2.4. Taguchi Method. Determining key factors is helpful for promoting experimental efficiency, and the traditional trialand-error method lacked overall planning, which although it could provide large amounts of data, these were the least discussed and analyzed. In addition, such experiments are time consuming and waste production costs. Moreover, control of experimental conditions was not simple. In order to obtain higher photocatalytic performance of photocatalysts, the Taguchi method was adopted for experimental design. For this purpose, critical conditions were selected and applied in the experimental planning in order to determine the optimal experimental parameters promoting a photocatalytic performance of the photocatalysts.

By orthogonal array, useful statistical data and reliable effects of factors can be obtained in the least number of experiments. However, full factorial experiments require too many experimental repetitions, while fractional factorial experimental method is too complex. L9, which represents the nine experiments to be conducted, was selected in this research.

The basic purpose of parameter design is to determine a group of optimal experimental parameters. By the Taguchi method, quality characteristics and removal rate were transformed into an SN ratio, which is useful in the estimation of statistical efficiency quantity. Photocatalysts, able to yield higher removal rates, meet the requirements of this study. Therefore, it is the best to have large quality characteristics. The SN ratio of the larger-the-better is defined as

$$
\eta=-10 \log \sum \frac{1}{n}\left(\frac{1}{y_{i}}\right)^{2}
$$

where $y_{i}$ represents value of quality; $n$ represents the total number of experiments.

Experiments for experimental planning design, according to an orthogonal array, can create the data required for the orthogonal array. Then, a response table can be established by transformation of the data from the orthogonal array experiments into SN ratios. The method selected for the transformation depends on the quality requested. Each average response, $\bar{F}_{i}$ of $F$, can be calculated. Then, the value of main effect, $\Delta F$ of each $F$, is calculated. A response table comprised of these data can be applied to analyze the effects of each factor. A larger $\Delta F$ indicates a larger effect on quality characteristics; inversely, a less $\Delta F$ indicates a lesser effect on quality characteristics. The calculation is as follows:

$$
\begin{gathered}
\bar{F}_{i}=\frac{1}{m} \sum_{j=1}^{m} y_{i j}, \\
\Delta F=\max \left\{\bar{F}_{1}, \bar{F}_{2}, \ldots, \bar{F}_{n}\right\}-\min \left\{\bar{F}_{1}, \bar{F}_{2}, \ldots, \bar{F}_{n}\right\},
\end{gathered}
$$

where $n$ represents level of factor; $m$ represents the total number of level $i ; y_{i}$ represents SN ratio of level $i$.

Confirmation experiments are to verify the reasonability of the constructed mathematical mode. Applying additional modes, using the level values of optimal factors, can predict the $\mathrm{SN}$ ratios under optimal conditions. The calculation is as follows:

$$
\widehat{\mathrm{SN}}=\bar{T}+\sum_{i=1}^{n}\left(F_{i}-\bar{T}\right)
$$

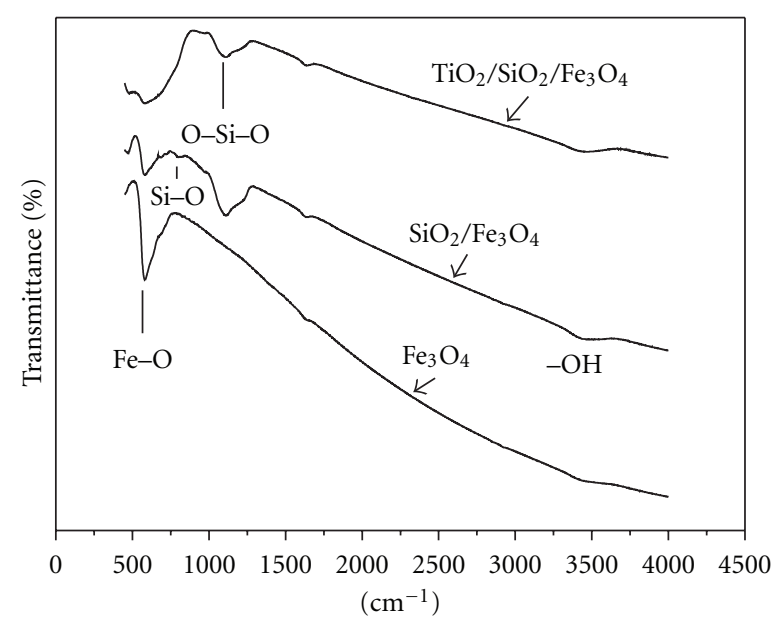

Figure 2: FTIR spectra of $\mathrm{Fe}_{3} \mathrm{O}_{4}, \mathrm{SiO}_{2} / \mathrm{Fe}_{3} \mathrm{O}_{4}$, and $\mathrm{TiO}_{2} / \mathrm{SiO}_{2} /$ $\mathrm{Fe}_{3} \mathrm{O}_{4}$.

where $\bar{T}$ represents average of all $\mathrm{SN}$ ratios; $F_{i}$ represents $\mathrm{SN}$ ratio of experimental parameters.

To evaluate each observed value, its confidence interval must be calculated. The formula for calculating the confidence interval of the average of the expected values from confirmation experiments is as follows:

$$
\mathrm{CI}=\sqrt{F_{\alpha ; 1, \nu_{2}} \times M S E \times\left(\frac{1}{n_{\mathrm{eff}}}+\frac{1}{r}\right)},
$$

where $F_{\alpha ; 1, \nu_{2}}$ represents $F$ value of the apparent level $\alpha$; $\alpha$ represents apparent level with confidence level $1-\alpha ; \nu_{2}$ represents freedom of the error; MSE represents variance of error; $n_{\text {eff }}$ represents the effective observed value; $r$ represents the number of confirmation experiments, $r \neq 0$.

Finally, a CI of $95 \%$ is used to verify whether the predicted average value is acceptable or not, the verification equation is:

$$
\widehat{\mathrm{SN}}-\mathrm{CI} \leq \mu \leq \widehat{\mathrm{SN}}+\mathrm{CI}
$$

\section{Results and Discussion}

3.1. Surface Characteristics of Magnetic Photocatalyst. The FTIR spectra of $\mathrm{Fe}_{3} \mathrm{O}_{4}, \mathrm{SiO}_{2} / \mathrm{Fe}_{3} \mathrm{O}_{4}$, and the prepared magnetic photocatalyst $\left(\mathrm{TiO}_{2} / \mathrm{SiO}_{2} / \mathrm{Fe}_{3} \mathrm{O}_{4}\right)$ are as shown in Figure 2. The result exhibits two basic characteristic peaks of $\mathrm{Fe}_{3} \mathrm{O}_{4}, \mathrm{SiO}_{2} / \mathrm{Fe}_{3} \mathrm{O}_{4}$, and $\mathrm{TiO}_{2} / \mathrm{SiO}_{2} / \mathrm{Fe}_{3} \mathrm{O}_{4}$ at about $3300 \mathrm{~cm}^{-1}$ (O-H stretching) and $550 \mathrm{~cm}^{-1}$ ( $\mathrm{Fe}-\mathrm{O}$ vibration), which were attributed to the presence of $\mathrm{FeOH}$ in $\mathrm{Fe}_{3} \mathrm{O}_{4}$ [24]. The peak at $1100 \mathrm{~cm}^{-1}$ was attributed to the $\mathrm{Si}-\mathrm{O}-$ $\mathrm{Si}$ bond stretching of $\mathrm{SiO}_{2} / \mathrm{Fe}_{3} \mathrm{O}_{4}$ and $\mathrm{TiO}_{2} / \mathrm{SiO}_{2} / \mathrm{Fe}_{3} \mathrm{O}_{4}$. This result confirms that $\mathrm{SiO}_{2}$ was successfully coated on $\mathrm{Fe}_{3} \mathrm{O}_{4}$. Figures 3(a) and 3(b) showed the SEM micrographs of the $\mathrm{Fe}_{2} \mathrm{O}_{3} / \mathrm{SiO}_{2}$ and $\mathrm{Fe}_{2} \mathrm{O}_{3} / \mathrm{SiO}_{2} / \mathrm{TiO}_{2}$. SEM micrographs indicate that the particles on the coatings aggregated without significant difference.

The magnetic properties of the $\mathrm{SiO}_{2} / \mathrm{Fe}_{3} \mathrm{O}_{4}$ and $\mathrm{Fe}_{3} \mathrm{O}_{4}$ cores were measured with a vibrating sample magnetometer 


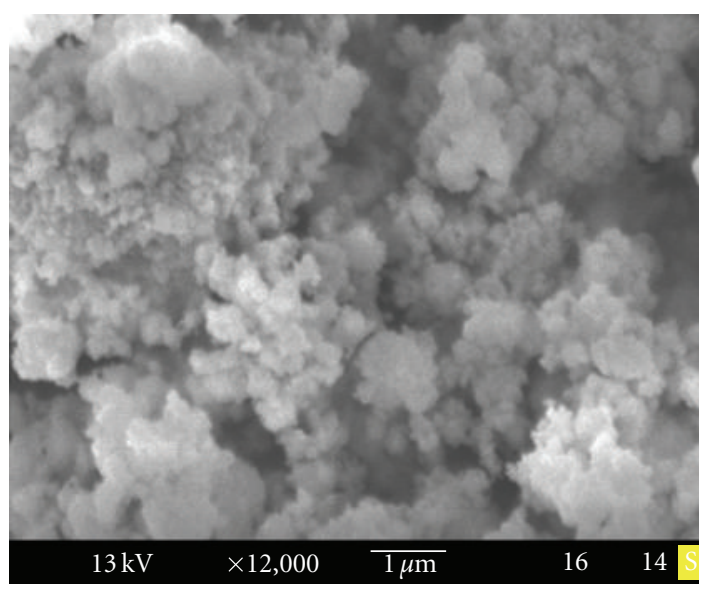

(a)

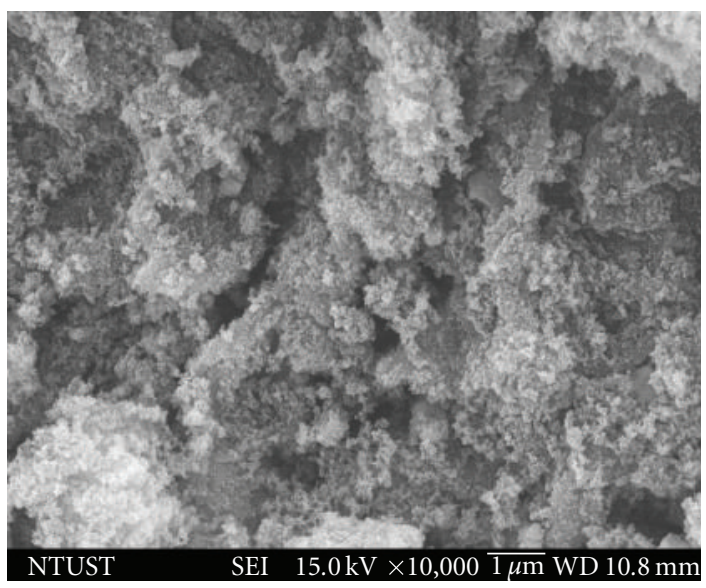

(b)

Figure 3: SEM images of (a) $\mathrm{Fe}_{2} \mathrm{O}_{3} / \mathrm{SiO}_{2}$ and (b) $\mathrm{Fe}_{2} \mathrm{O}_{3} / \mathrm{SiO}_{2} / \mathrm{TiO}_{2}$.

(VSM), as shown in Figure 4. The $\mathrm{M}-\mathrm{H}$ plots showed the change in Ms of the particles after the incorporation of $\mathrm{SiO}_{2}$ and $\mathrm{TiO}_{2}$ shell. A decrease in Ms from 61.8 to 28.0 emu g ${ }^{-1}$ was observed in $\mathrm{SiO}_{2} / \mathrm{Fe}_{3} \mathrm{O}_{4}$. The decreased mass saturation magnetization was ascribed to the contribution of the nonmagnetic $\mathrm{SiO}_{2}$ and $\mathrm{TiO}_{2}$ shell to the total mass of particles. This observation is similar to those in reports where the attached gold shell was found to lower the saturation magnetization of magnetite particles [25]. The results indicated that the prepared samples exhibited paramagnetic behaviors at room temperature [11]. The paramagnetic behaviors of the prepared $\mathrm{TiO}_{2} / \mathrm{SiO}_{2} / \mathrm{Fe}_{3} \mathrm{O}_{4}$ gave rise to the magnetic photocatalyst $\mathrm{TiO}_{2} / \mathrm{SiO}_{2} / \mathrm{Fe}_{3} \mathrm{O}_{4}$, which could be separated more easily through the application of a magnetic field.

According to the database of the Joint Committee on Powder Diffraction Standards (JCPDS), the XRD pattern of a standard $\mathrm{Fe}_{3} \mathrm{O}_{4}$ crystal with a spinel structure has six characteristic peaks at $2 \theta=30.1^{\circ}, 35.5^{\circ}, 43.1^{\circ}, 53.4^{\circ}, 57.0^{\circ}$, and $62.6^{\circ}$, which are attributed to the (2 20$),(311),(400)$, (4 22 2), (5 11 1), and (4 40 ) phases of $\mathrm{Fe}_{3} \mathrm{O}_{4}$, respectively, as shown in Figure 5. Based on the XRD spectra, the crystalline phases could be categorized into two primary components,

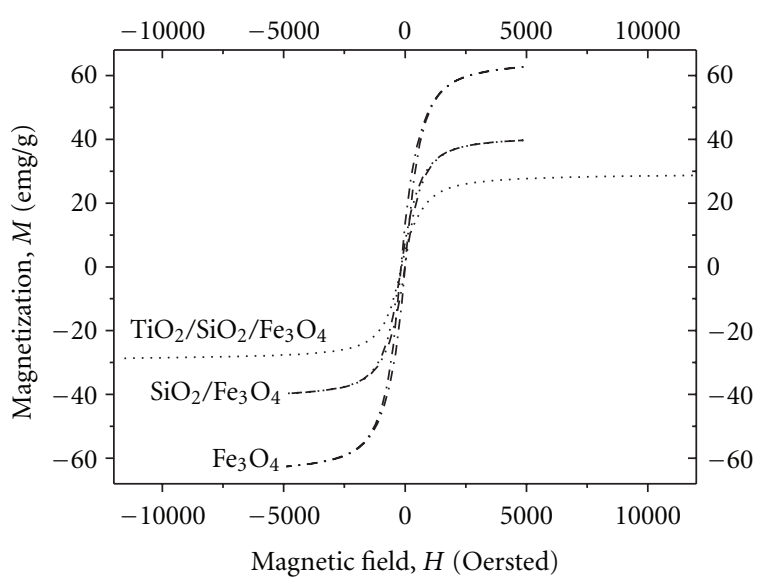

FIGURE 4: Magnetization versus applied magnetic field.

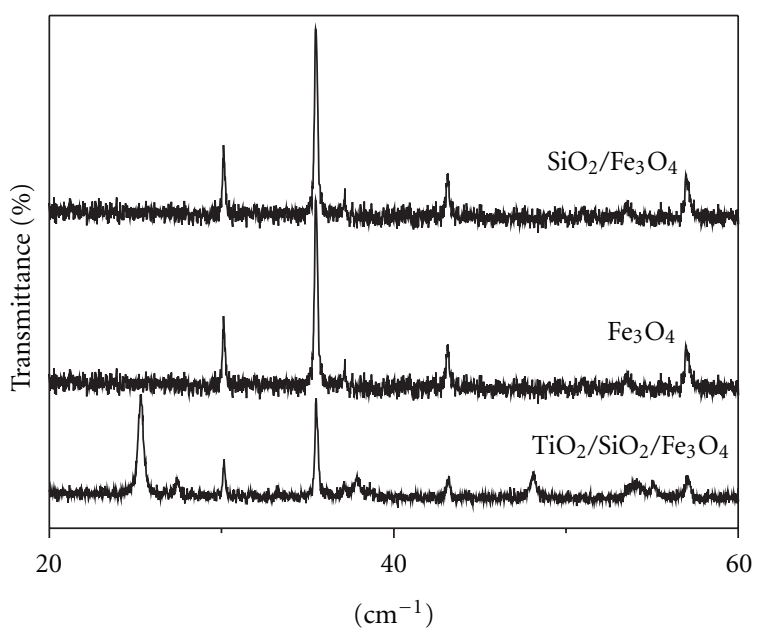

FIgURE 5: XRD spectra of the photocatalyst coatings.

an anatase (A) and a rutile (R) phase, and represented the intensity of the strongest anatase reflection of (101) plane at $2 \theta=25.3^{\circ} \pm 0.1^{\circ}$, anatase reflection of (200) plane at $2 \theta=48.0^{\circ} \pm 0.1^{\circ}$, and the intensity of the strongest rutile reflection of (110) plane at $2 \theta=27.4^{\circ} \pm 0.1^{\circ}$. Additionally, the anatase phase of $\mathrm{TiO}_{2}$ crystal is a tetragonal system in lattice geometry. The analysis results of the starting material $\mathrm{Fe}_{3} \mathrm{O}_{4}$, and $\mathrm{TiO}_{2} / \mathrm{SiO}_{2} / \mathrm{Fe}_{3} \mathrm{O}_{4}$ fitted the pattern exhibited by standard magnetite. Therefore, it can be concluded that the magnetite, modified with $\mathrm{SiO}_{2}$, also has a spinel structure, and that the modification does not cause a phase change in $\mathrm{Fe}_{3} \mathrm{O}_{4}$.

3.2. Photocatalytic Decomposition of Benzoic Acid. The photoactivity of $\mathrm{TiO}_{2} / \mathrm{SiO}_{2} / \mathrm{Fe}_{3} \mathrm{O}_{4}$ was sensitively influenced by the temperatures of calcination, as shown in Table 1 . The reaction rate constant of benzoic acid under UV light irradiation was decreased with the increased calcination temperature. The reasons described that the surface area of $\mathrm{SiO}_{2} / \mathrm{TiO}_{2} / \mathrm{Fe}_{3} \mathrm{O}_{4}$ decreased as the calcinations temperature 
TABLE 1: Effect of calcinations temperature on reaction rate constant and surface area.

\begin{tabular}{lccc}
\hline $\begin{array}{l}\text { Temperature } \\
\left({ }^{\circ} \mathrm{C}\right)\end{array}$ & $\begin{array}{c}k \\
\left(\mathrm{~min}^{-1}\right)\end{array}$ & $\begin{array}{c}\text { Surface area } \\
\left(\mathrm{m}^{2} \mathrm{~g}^{-1}\right)\end{array}$ & $\begin{array}{c}\text { Recovery } \\
(\%)\end{array}$ \\
\hline 350 & 0.0059 & 32.75 & 93.7 \\
550 & 0.0034 & 21.35 & 94.6 \\
750 & 0.0005 & 9.29 & 96.4 \\
\hline
\end{tabular}

raised from 350 to $750^{\circ} \mathrm{C}$, in particular, the sample calcined at $750^{\circ} \mathrm{C}$ were almost completely inactive.

When the calcination temperature is over $700^{\circ} \mathrm{C}$, the photocatalytic activity of thin films decreases, which is due to the formation of rutile and the sintering and growth of $\mathrm{TiO}_{2}$ crystallites resulting in the decrease of surface area [26]. Furthermore, the paramagnetic behaviors of the magnetic photocatalyst $\mathrm{TiO}_{2} / \mathrm{SiO}_{2} / \mathrm{Fe}_{3} \mathrm{O}_{4}$, could be separated more easily by the application of a magnetic field. More than $90 \%$ of the magnetic photocatalyst with various temperatures of calcination was recovered and easily redispersed in aqueous solution for reuse.

The $\mathrm{pH}$ of the aqueous solution is one of the important environmental parameters significantly influencing the physicochemical properties of semiconductors, including the charge on the $\mathrm{TiO}_{2}$ particle, the aggregation numbers of particles, and the positions of the conductance and valence bands [23]. The degradation of benzoic acid increased as $\mathrm{pH}$ value increased from 3 to 10 . No adsorption was recorded at $\mathrm{pH}>6$ as both catalyst and the substrate are negatively charged, since benzoic acid adsorption onto catalyst is not favored at neutral or alkaline conditions [27]. From experimental results [28], $0.1 \mathrm{mM}$ of $o$-methylbenzoic acid could be completely decomposed in $2 \mathrm{~h}$. The reaction was faster with lowering $\mathrm{pH}$ and was found to be apparent first-order following Langmuir-Hinshelwood model. Chen et al. [29] also obtained similar results, the reaction rate increased from acidic to a weak alkaline solution with $\mathrm{TiO}_{2}$ photocatalyst. The surface of $\mathrm{TiO}_{2}$ is negatively charged in solutions with $\mathrm{pH}$ greater than 6, because the point of zero charge of $\mathrm{TiO}_{2}$ was determined to be about 6.0. The disassociated benzoic acid species also presented negative charge in solutions with $\mathrm{pH}$ greater than 4.2. Therefore, there is repulsion between a $\mathrm{TiO}_{2}$ surface and benzoic acid.

3.3. Taguchi Experimental Plan. Before experiments were conducted, control factors and their levels must be first decided. Therefore, $\mathrm{pH}$, weight ratio of $\mathrm{TiO}_{2} / \mathrm{SiO}_{2}\left(\mathrm{Fe}_{3} \mathrm{O}_{4}\right)$, and calcined temperatures of $\mathrm{TiO}_{2} / \mathrm{SiO}_{2} / \mathrm{Fe}_{3} \mathrm{O}_{4}$ were selected as control factors, and removal rate was chosen as the quality characteristic. Control factors and their levels are as shown in Table 2, in which the levels of the $\mathrm{pH}$ are set to a sliding level to reduce interactions; which are shown in Table 3. Because a higher removal rate is better, $\mathrm{SN}$ ratio was selected, as shown in (1).

According to Table 2, the selected control factors and their levels were applied in the L9 orthogonal array. Nine groups of experiments were conducted according to the L9 orthogonal array. Each group of experiments was repeated
TABLE 2: Factors and their levels for the experiments.

\begin{tabular}{lccc}
\hline Factor & Level 1 & Level 2 & Level 3 \\
\hline $\begin{array}{l}\mathrm{A}: \mathrm{pH}^{\mathrm{a}} \\
\mathrm{B}: \text { weight ratio of } \mathrm{TiO}_{2} /\end{array}$ & $\mathrm{A} 1$ & $\mathrm{~A} 2$ & $\mathrm{~A} 3$ \\
$\mathrm{SiO}_{2}\left(\mathrm{Fe}_{3} \mathrm{O}_{4}\right)$ & 1 & 3 & 5 \\
$\begin{array}{l}\mathrm{C} \text { : calcined temperatures } \\
\text { of } \mathrm{TiO}_{2} / \mathrm{SiO}_{2} / \mathrm{Fe}_{3} \mathrm{O}_{4}\end{array}$ & $350^{\circ} \mathrm{C}$ & $550^{\circ} \mathrm{C}$ & $750{ }^{\circ} \mathrm{C}$ \\
\hline
\end{tabular}

${ }^{\mathrm{a}}$ The numbers are explained in Table 2.

TABLE 3: pH levels.

\begin{tabular}{lccc}
\hline Number $^{\mathrm{a}}$ & Level 1 & Level 2 & Level 3 \\
\hline A1 & 3 & 5 & 7 \\
A2 & 5 & 7 & 9 \\
A3 & 7 & 9 & 10 \\
\hline
\end{tabular}

three times, and the removal rate of each group was recorded, with twenty-seven data collected. These data were calculated according to (1) to yield SN ratios. The results are shown, as in Table 4. Next, SN ratios were computed according to (2) to yield the main effect of each control factor. A response table was drawn out, as indicated by Table 5 . The optimal conditions determined were $\mathrm{A} 1, \mathrm{~B} 1$, and $\mathrm{C} 1$; namely, $\mathrm{pH}$ is 3, weight ratio of $\mathrm{TiO}_{2} / \mathrm{SiO}_{2}\left(\mathrm{Fe}_{3} \mathrm{O}_{4}\right)$ is 1 , and calcined temperature of $\mathrm{TiO}_{2} / \mathrm{SiO}_{2} / \mathrm{Fe}_{3} \mathrm{O}_{4}$ is $350^{\circ} \mathrm{C}$. In addition, the effect of each parameter on the removal rate under different levels was therefore known. Factor $\mathrm{C}$, calcined temperatures of $\mathrm{TiO}_{2} / \mathrm{SiO}_{2} / \mathrm{Fe}_{3} \mathrm{O}_{4}$, gave the greatest effect, and $\mathrm{A}, \mathrm{pH}$, provided the second greatest effect.

The surface area-decreased effect was similar to the conclusion of photocatalytic mineralization of phenol on $\mathrm{TiO}_{2} \mathrm{P} 25$, as reported by [30]. They suggested that the amount of the surface-adsorbed water and hydroxyl groups, which was oxidized to a hydroxyl radical $\left(\mathrm{OH}^{-}\right)$, was decreased via thermal treatment. Due to the charge on the $\mathrm{TiO}_{2}$ particle, the aggregation numbers of particles and disassociated species of contamination, and the optimal $\mathrm{pH}$ value of the aqueous solution were determined during the of photocatalytic oxidation of contamination [29].

To further understand the effect of each factor on the removal rates of photocatalysts, the removal rates were analyzed by analysis of variance (ANOVA) [31], which was designed to determine the error of the variance in order to know what extent the effect of each factor has on photocatalysts. The result obtained would be useful in the evaluation of experimental errors, as shown in Table 5.

A larger F-ratio indicates that there is a larger factor effect. F-ratio is often larger than 2, indicating that there is a not small factor effect. An F-ratio larger than 4 indicates that there is a very large factor effect. From Table 6, the result shown in the analysis of variance indicates that removal rate is less affected by factor B. On the contrary, the F-ratios of factors $\mathrm{C}$ and $\mathrm{A}$ are larger than 4 ; therefore, they are significant factors.

The SN ratio of the optimal experimental parameters are calculated from removal rates, $55.3 \%(-5.15 \mathrm{~dB})$ obtained from (3), (4), and (5), was confirmed by three experiments. 
TABLE 4: The L9 experimental layout and experimental results.

\begin{tabular}{|c|c|c|c|c|c|}
\hline \multirow{2}{*}{ Trial no. } & \multicolumn{3}{|c|}{ Factor assignment } & \multirow{2}{*}{ Average (\%) } & \multirow{2}{*}{$\mathrm{SN}$ ratio $(\mathrm{dB})$} \\
\hline & $\mathrm{A}$ & B & C & & \\
\hline 1 & 3 & 1 & $350^{\circ} \mathrm{C}$ & 50.0 & -6.02 \\
\hline 2 & 5 & 3 & $550^{\circ} \mathrm{C}$ & 33.0 & -9.63 \\
\hline 3 & 7 & 5 & $750^{\circ} \mathrm{C}$ & 3.8 & -28.40 \\
\hline 4 & 5 & 1 & $550^{\circ} \mathrm{C}$ & 24.2 & -12.32 \\
\hline 5 & 7 & 3 & $750^{\circ} \mathrm{C}$ & 7.7 & -22.27 \\
\hline 6 & 9 & 5 & $350^{\circ} \mathrm{C}$ & 23.8 & -12.47 \\
\hline 7 & 7 & 1 & $750^{\circ} \mathrm{C}$ & 4.9 & -26.20 \\
\hline 8 & 9 & 3 & $350^{\circ} \mathrm{C}$ & 10.8 & -19.33 \\
\hline 9 & 10 & 5 & $550^{\circ} \mathrm{C}$ & 5.0 & -26.02 \\
\hline
\end{tabular}

TABLE 5: Average effect response for SN ratios.

\begin{tabular}{lccc}
\hline & $\mathrm{A}$ & $\mathrm{B}$ & $\mathrm{C}$ \\
\hline Level 1 & -14.68 & -14.85 & -12.61 \\
Level 2 & -15.69 & -17.08 & -15.99 \\
Level 3 & -23.85 & -22.30 & -25.62 \\
Effect & 9.16 & 7.45 & 13.02 \\
\hline Rank & $\mathbf{2}$ & $\mathbf{3}$ & $\mathbf{1}$ \\
\hline
\end{tabular}

All SN ratios of removal rates fall in the 95\% confidence interval, $-24.0248 \leq \mu \leq 13.0008 \mathrm{~dB}$, which indicates that the experiment is reproducible and reliable.

Benzoic acid, present in an aqueous solution at $\mathrm{pH} 3$, could be decomposed higher than $50 \%$ within approximately $120 \mathrm{~min}$ of the reaction time, as shown in Figure 6. The decomposition of benzoic acid by the $\mathrm{UV} / \mathrm{TiO}_{2} / \mathrm{SiO}_{2} / \mathrm{Fe}_{3} \mathrm{O}_{4}$ process was higher than that of the $\mathrm{UV} / \mathrm{TiO}_{2}$ (P25) process in this study. This could be explained by the addition of $\mathrm{SiO}_{2}$ into photocatalysts retarding the crystallization of anatase phase. The addition of a second metal oxide, such as $\mathrm{SiO}_{2}$, $\mathrm{ZrO}_{2}$, and $\mathrm{Al}_{2} \mathrm{O}_{3}$, was also found to be an effective route to improve the thermal stability and UV photocatalytic activity of $\mathrm{TiO}_{2}[32,33]$. Among them, $\mathrm{SiO}_{2}-\mathrm{TiO}_{2}$ materials were most widely investigated in the photocatalysis field, as they exhibited higher photocatalytic activity than pure $\mathrm{TiO}_{2}$. Moreover, this $\mathrm{SiO}_{2}$ layer inhibits the iron oxide core becoming a recombination center of electrons and holes. The transfer of photogenerated electrons and holes from $\mathrm{TiO}_{2}$ to $\mathrm{Fe}_{3} \mathrm{O}_{4}$ can be completely inhibited by introducing a wide bandgap $\mathrm{SiO}_{2}$ layer as an electronic barrier $[15,16]$. Furthermore, silica is also a good adsorbent towards organic molecules. The enhanced adsorption for $\mathrm{RhB}$ on silica adsorbent layer significantly increases the local concentration of $\mathrm{RhB}$ near the porous titania photoactive layer relative to the bulk solution [34].

\section{Conclusions}

The optimal experimental parameters of $\mathrm{TiO}_{2}$ preparation for the removal rate of photocatalysts were concluded as $\mathrm{pH}$ is 3, weight ratio of $\mathrm{TiO}_{2} / \mathrm{SiO}_{2}\left(\mathrm{Fe}_{3} \mathrm{O}_{4}\right)$ is 1 , and calcined temperatures of $\mathrm{TiO}_{2} / \mathrm{SiO}_{2} / \mathrm{Fe}_{3} \mathrm{O}_{4}$ are $350^{\circ} \mathrm{C}$. The $\mathrm{SN}$ ratios

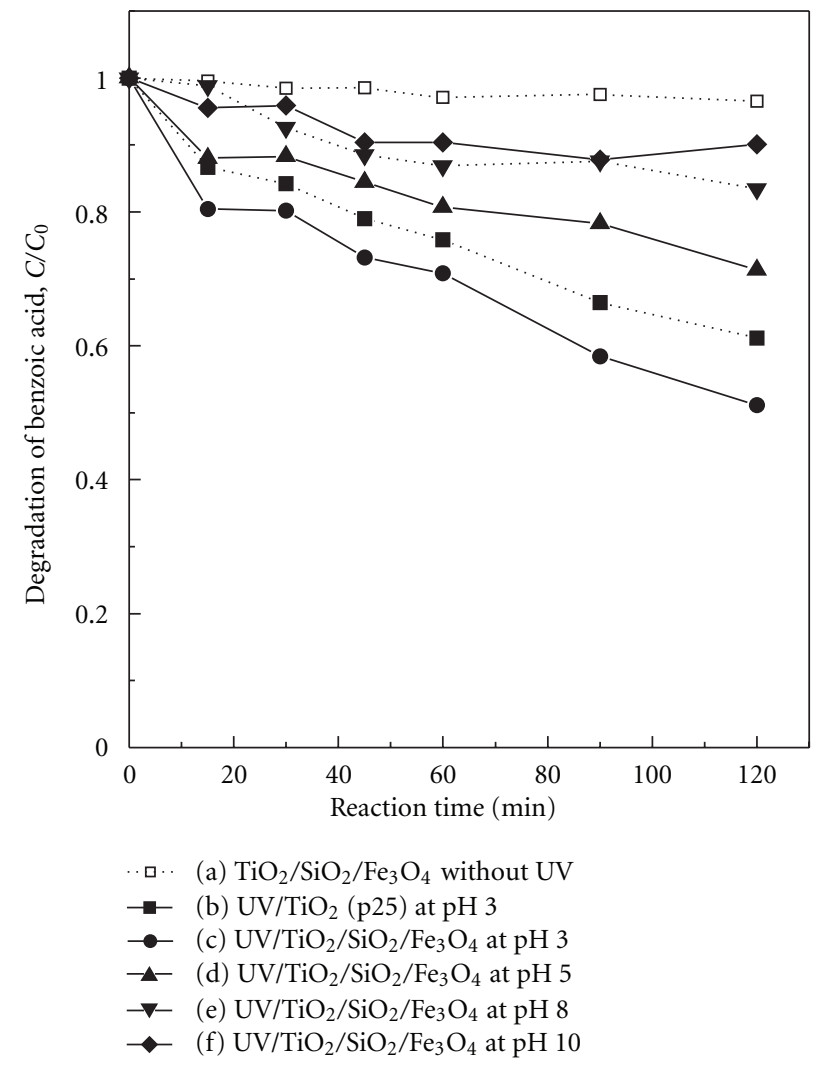

FIGURE 6: Degradation of benzoic acid by UV/magnetic photocatalyst process at solution temperature $=20^{\circ} \mathrm{C}$, the initial concentration of benzoic acid $=10 \mathrm{mg} \mathrm{L}^{-1}, \mathrm{TiO}_{2} / \mathrm{SiO}_{2} / \mathrm{Fe}_{3} \mathrm{O}_{4}=0.5 \mathrm{~g} \mathrm{~L}^{-1}$.

in a confidence interval of $95 \%$, as provided in the confirmation experiments, indicate the selected significant factor are reasonable, the results are reproducible, and in particular, the experiments are reliable. In addition, the result of analysis of variance indicates calcined temperature of $\mathrm{TiO}_{2} / \mathrm{SiO}_{2} / \mathrm{Fe}_{3} \mathrm{O}_{4}$ is the most significant factor. The deviation contributed by Table 6 to error is less than $50 \%$, which indicates that there were important factors in the experiments, rendering the results precise. This research provides a method suitable for optimizing other experimental parameters to promote experimental efficiency. Furthermore, the paramagnetic behaviors 
TABLE 6: ANOVA of SN ratio for the removal rate of photocatalysts.

\begin{tabular}{lcccccc}
\hline Source & Degree of freedom & Sum of squares & Variance & $F$-ratio & Pure sum of squares & Contribution $(\%)$ \\
\hline A & 2 & 151.61 & 75.81 & 6.57 & 128.54 & 23.98 \\
B & 2 & 87.75 & 43.87 & 3.80 & 64.67 & 12.06 \\
C & 2 & 273.67 & 136.83 & 11.86 & 250.59 & 46.74 \\
Error & 2 & 23.07 & 11.54 & & 46.15 & 17.22 \\
\hline Total & 8 & 536.10 & & & & 100 \\
\hline
\end{tabular}

of the magnetic photocatalyst $\mathrm{TiO}_{2} / \mathrm{SiO}_{2} / \mathrm{Fe}_{3} \mathrm{O}_{4}$ could be separated more easily by the application of a magnetic field. More than $90 \%$ of the magnetic photocatalyst was recovered and easily redispersed in aqueous solution for reuse at various $\mathrm{pH}$ levels.

\section{Acknowledgment}

This research was supported by the National Science Council, Taiwan, under Grant no. NSC 99-2622-E-562-002-CC3.

\section{References}

[1] A. Wibbertmann, J. Kielhorn, G. Koennecker, I. Mangelsdorf, and C. Melber, "Concise international chemical assessment document 26: benzoic acid and sodium benzoate," Concise International Chemical Assessment Documents, no. 26, pp. 148, 2000.

[2] F. Chen, J. Zhao, and H. Hidaka, "Highly selective deethylation of Rhodamine B: adsorption and photooxidation pathways of the dye on the $\mathrm{TiO}_{2} / \mathrm{SiO}_{2}$ composite photocatalyst," International Journal of Photoenergy, vol. 5, no. 4, pp. 209-217, 2003.

[3] B. Y. Lee, S. W. Kim, S. C. Lee, H. H. Lee, and S. J. Choung, "Photocatalytic decomposition of gaseous formaldehyde using $\mathrm{TiO}_{2}, \mathrm{SiO}_{2}-\mathrm{TiO}_{2}$ and $\mathrm{Pt}-\mathrm{TiO}_{2}$," International Journal of Photoenergy, vol. 5, no. 1, pp. 21-25, 2003.

[4] H. W. Chen, C. S. Chiou, and G. B. Hong, "Effect of magnetic catalysts on kinetic behavior of reactive black 5 decomposition by $\mathrm{O}_{3} / \mathrm{H}_{2} \mathrm{O}_{2}$ process," Journal of Chemical Technology \& Biotechnology, vol. 86, no. 2, pp. 299-305, 2010.

[5] J. Gamage and Z. Zhang, "Applications of photocatalytic disinfection," International Journal of Photoenergy, vol. 2010, Article ID 764870, 11 pages, 2010.

[6] M.L. Chen and W. C. Oh, "The improved photocatalytic properties of methylene blue for $\mathrm{V}_{2} \mathrm{O}_{3} / \mathrm{CNT} / \mathrm{TiO}_{2}$ composite under visible light," International Journal of Photoenergy, vol. 2010, Article ID 264831, 5 pages, 2010.

[7] Q. Xiang, J. Yu, and M. Jaroniec, "Tunable photocatalytic selectivity of $\mathrm{TiO}_{2}$ films consisted of flower-like microspheres with exposed $\{001\}$ facets," Chemical Communications, vol. 47, no. 15, pp. 4532-4534, 2011.

[8] S. Liu, J. Yu, and M. Jaroniec, "Tunable photocatalytic selectivity of hollow $\mathrm{TiO}_{2}$ microspheres composed of anatase polyhedra with exposed $\{001\}$ facets," Journal of the American Chemical Society, vol. 132, no. 34, pp. 11914-11916, 2010.

[9] J. A. Byrne, P. A. Fernandez-Ibañez, P. S.M. Dunlop, D. M.A. Alrousan, and J. W.J. Hamilton, "Photocatalytic enhancement for solar disinfection of water: a review," International Journal of Photoenergy, vol. 2011, Article ID 798051, 12 pages, 2011.

[10] J. Yu, X. Yu, B. Huang, X. Zhang, and Y. Dai, "Hydrothermal synthesis and visible-light photocatalytic activity of novel cage-like ferric oxide hollow spheres," Crystal Growth and Design, vol. 9, no. 3, pp. 1474-1480, 2009.

[11] J. Xu, Y. Ao, D. Fu, and C. Yuan, "Low-temperature preparation of anatase titania-coated magnetite," Journal of Physics and Chemistry of Solids, vol. 69, no. 8, pp. 1980-1984, 2008.

[12] S. Watson, J. Scott, D. Beydoun, and R. Amal, "Studies on the preparation of magnetic photocatalysts," Journal of Nanoparticle Research, vol. 7, no. 6, pp. 691-705, 2005.

[13] H. Yang, X. Mao, Y. Guo et al., "Porous $\alpha-\mathrm{Fe}_{2} \mathrm{O}_{3}$ nanostructures with branched topology: growth, formation mechanism, and properties," CrystEngComm, vol. 12, no. 6, pp. 1842-1849, 2010.

[14] S. Ni, X. Wang, G. Zhou et al., "Size controlled and morphology tuned fabrication of $\mathrm{Fe}_{3} \mathrm{O}_{4}$ nanocrystals and their magnetic properties," Journal of Alloys and Compounds, vol. 505, no. 2, pp. 727-732, 2010.

[15] D. Beydoun, R. Amal, G. K. C. Low, and S. McEvoy, "Novel photocatalyst: titania-coated magnetite. activity and photodissolution," Journal of Physical Chemistry B, vol. 104, no. 18, pp. 4387-4396, 2000.

[16] X. Yu, S. Liu, and J. Yu, "Superparamagnetic $\gamma-\mathrm{Fe}_{2} \mathrm{O}_{3} / \mathrm{SiO}_{2} /$ $\mathrm{TiO}_{2}$ composite microspheres with superior photocatalytic properties," Applied Catalysis B, vol. 104, no. 1-2, pp. 12-20, 2011.

[17] G. Taguchi, Introduction to Quality Engineering, Asian Production Organization, Tokyo, Japan, 1986.

[18] G. Taguchi, E. A. Elsayed, and T. C. Hsiang, Quality Engineering in Production Systems, McGraw-Hill, New York, NY, USA, 1989.

[19] J. Zhou, D. Wu, and D. Guo, "Optimization of the production of thiocarbohydrazide using the Taguchi method," Journal of Chemical Technology and Biotechnology, vol. 85, no. 10, pp. 1402-1406, 2010.

[20] T. L. Su, H. W. Chen, C. M. Ma, and C. F. Lu, "Improving the combed yarn qualities of OE rotor by using Grey-Taguchi method," Fibres \& Textiles in Eastern Europe, vol. 85, no. 2, pp. 23-27, 2011.

[21] S. Mavruz and R. T. Ogulata, "Taguchi approach for the optimisation of the bursting strength of knitted fabrics," Fibres and Textiles in Eastern Europe, vol. 79, no. 2, pp. 78-83, 2010.

[22] A. B. Engin, Ö. Özdemir, M. Turan, and A. Z. Turan, "Color removal from textile dyebath effluents in a zeolite fixed bed reactor: determination of optimum process conditions using Taguchi method," Journal of Hazardous Materials, vol. 159, no. 2-3, pp. 348-353, 2008.

[23] J. G. Yu, H. G. Yu, B. Cheng, X. J. Zhao, J. C. Yu, and W. K. Ho, "The effect of calcination temperature on the surface microstructure and photocatalytic activity of $\mathrm{TiO}_{2}$ thin films prepared by liquid phase deposition," Journal of Physical Chemistry B, vol. 107, no. 50, pp. 13871-13879, 2003.

[24] K. Kabra, R. Chaudhary, and R. L. Sawhney, "Treatment of hazardous organic and inorganic compounds through 
aqueous-phase photocatalysis: a review," Industrial and Engineering Chemistry Research, vol. 43, no. 24, pp. 7683-7696, 2004.

[25] N. T. S. Phan and C. W. Jones, "Highly accessible catalytic sites on recyclable organosilane-functionalized magnetic nanoparticles: an alternative to functionalized porous silica catalysts," Journal of Molecular Catalysis A, vol. 253, no. 1-2, pp. 123-131, 2006.

[26] C. R. Vestal and Z. J. Zhang, "Atom transfer radical polymerization synthesis and magnetic characterization of $\mathrm{MnFe}_{2} \mathrm{O}_{4}$ / polystyrene core/shell nanoparticles," Journal of the American Chemical Society, vol. 124, no. 48, pp. 14312-14313, 2002.

[27] T. Velegraki and D. Mantzavinos, "Conversion of benzoic acid during $\mathrm{TiO}_{2}$-mediated photocatalytic degradation in water," Chemical Engineering Journal, vol. 140, no. 1-3, pp. 15-21, 2008.

[28] K. H. Wang, Y. H. Hsieh, C. H. Wu, and C. Y. Chang, “The pH and anion effects on the heterogeneous photocatalytic degradation of o-methylbenzoic acid in $\mathrm{TiO}_{2}$ aqueous suspension," Chemosphere, vol. 40, no. 4, pp. 389-394, 2000.

[29] H. W. Chen, Y. Ku, and Y. L. Kuo, "Effect of Pt/TiO 2 characteristics on temporal behavior of o-cresol decomposition by visible light-induced photocatalysis," Water Research, vol. 41, no. 10, pp. 2069-2078, 2007.

[30] N. R. C. Fernandes MacHado and V. S. Santana, "Influence of thermal treatment on the structure and photocatalytic activity of $\mathrm{TiO}_{2}$ P25," Catalysis Today, vol. 107-108, pp. 595-601, 2005.

[31] T. L. Su, H. W. Chen, and C. F. Lu, "Systematic optimization for the evaluation of the microinjection molding parameters of light guide plate with TOPSIS-based taguchi method," Advances in Polymer Technology, vol. 29, no. 1, pp. 54-63, 2010.

[32] X. Z. Fu, L. A. Clark, Q. Yang, and M. A. Anderson, "Enhanced photocatalytic performance of titania-based binary metal oxides: $\mathrm{TiO}_{2} / \mathrm{SiO}_{2}$ and $\mathrm{TiO}_{2} / \mathrm{ZrO}_{2}$," Environmental Science and Technology, vol. 30, no. 2, pp. 647-653, 1996.

[33] R. S. Sonawane, S. G. Hegde, and M. K. Dongare, "Preparation of titanium(IV) oxide thin film photocatalyst by sol-gel dip coating," Materials Chemistry and Physics, vol. 70, no. 3, pp. 744-750, 2002.

[34] C. Anderson and A. J. Bard, "An improved photocatalyst of $\mathrm{TiO}_{2} / \mathrm{SiO}_{2}$ prepared by a sol-gel synthesis," Journal of Physical Chemistry, vol. 99, no. 24, pp. 9882-9885, 1995. 


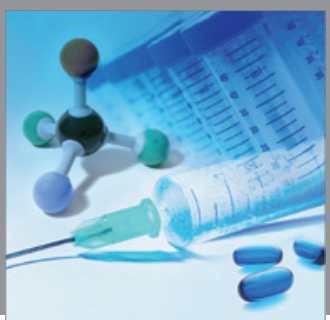

International Journal of

Medicinal Chemistry

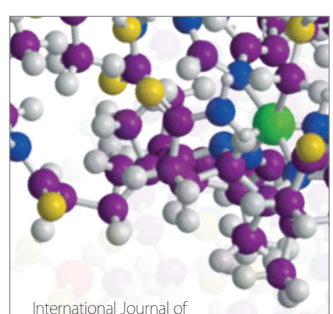

Carbohydrate Chemistry

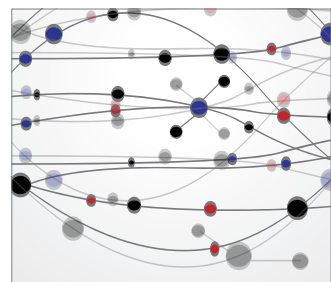

The Scientific World Journal
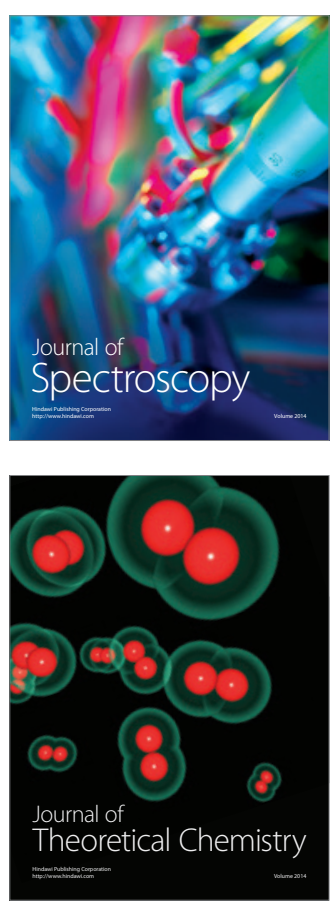
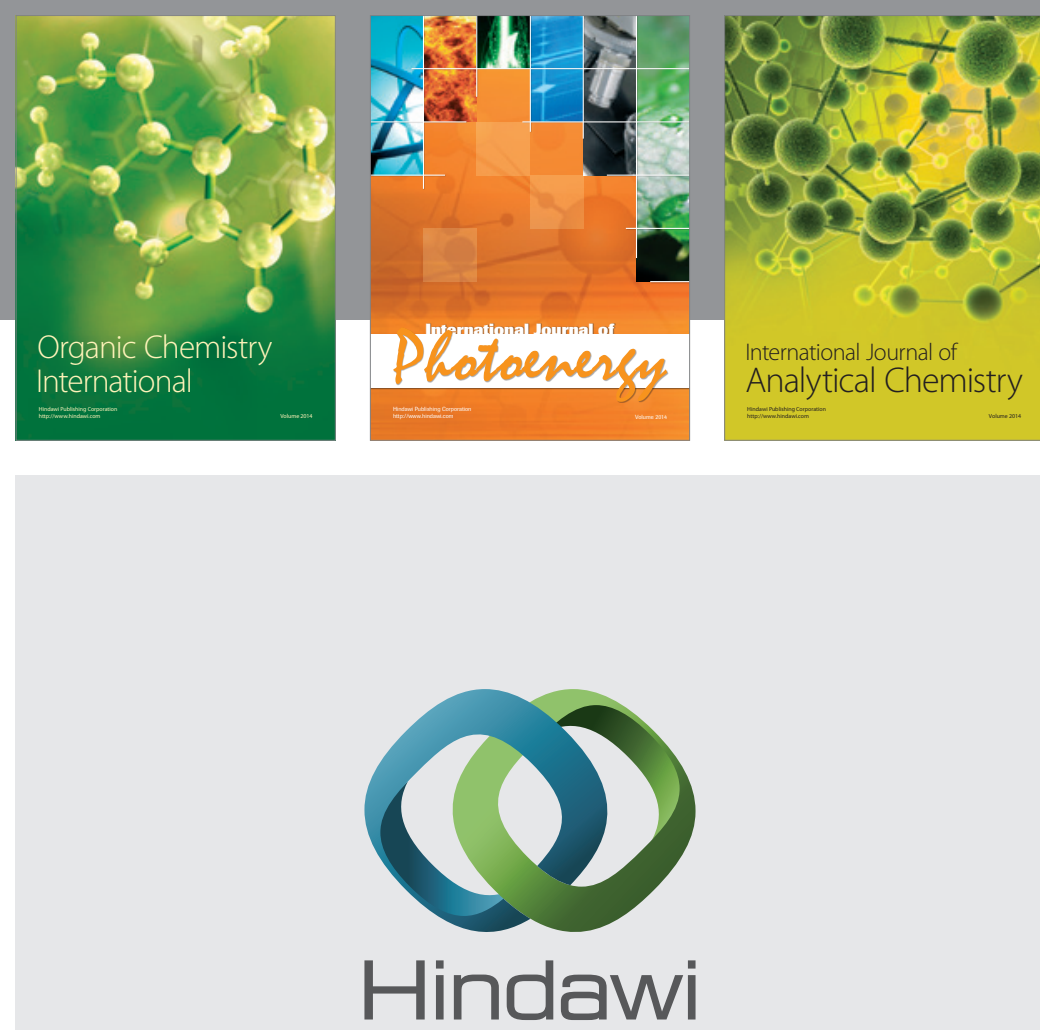

Submit your manuscripts at

http://www.hindawi.com
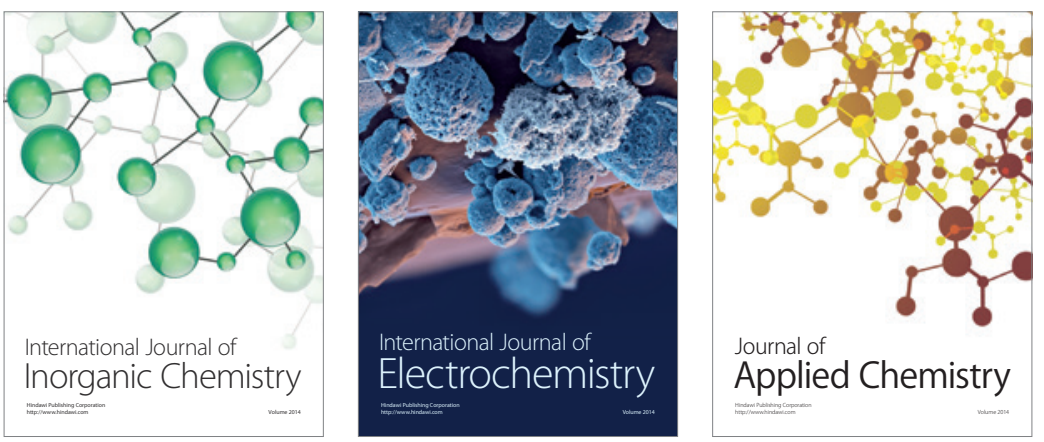

Journal of

Applied Chemistry
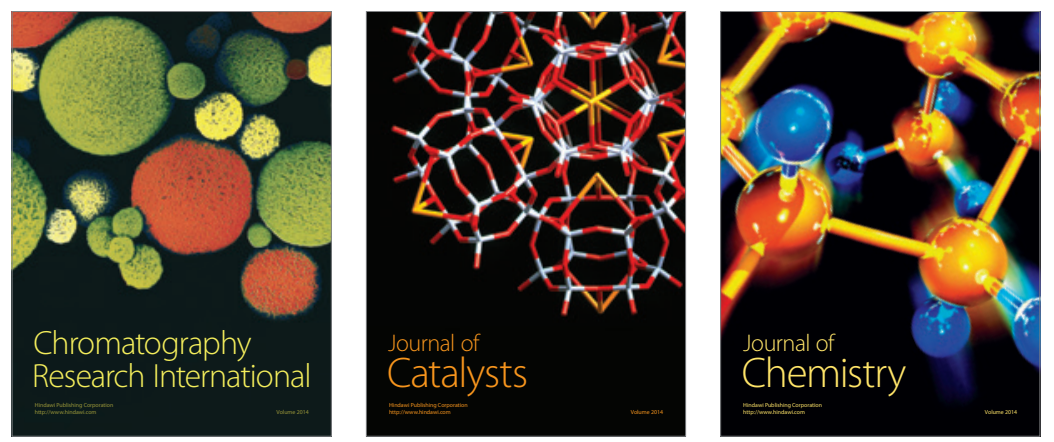
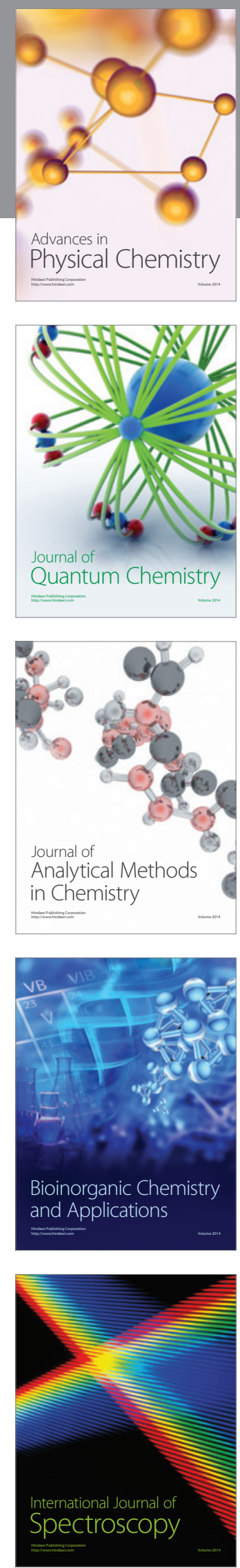